\title{
The potential of rainwater harvesting: A case of the city of Windhoek, Namibia
}

\author{
Festus Panduleni Nashima ${ }^{1, ~}$, Martin Hipondoka ${ }^{1}$, Inekela Iiyambo ${ }^{2}$, Johannes Hambia $^{3}$ \\ ${ }^{1}$ University of Namibia, Private Bag 13301, Windhoek, Namibia \\ ${ }^{2}$ Rossing Uranium of Namibia, Private Bag 5005, Swakopmund, Namibia \\ ${ }^{3}$ University of Namibia, Ogongo Campus, Private Bag 5520, Oshakati, Namibia
}

\section{Email address:}

fnashima@unam.na (F. P. Nashima),mhipondoka@unam.na (M. Hipondoka), inekelaiiyambo@yahoo.com (I. Iiyambo), jhambia@unam.na (J. Hambia)

\section{To cite this article:}

Festus Panduleni Nashima, Martin Hipondoka, Inekela Iiyambo, Johannes Hambia. The Potential of Rainwater Harvesting: A Case of the City of Windhoek, Namibia. Journal of Water Resources and Ocean Sciencs. Vol. 2, No. 6, 2013, pp. 170-174.

doi: 10.11648/j.wros.20130206.13

\begin{abstract}
Windhoek, Namibia's capital has experience for more than 25 years of novel approaches in integrated water management largely driven by the scarcity of water in the area. Notably absent in their approaches however, is the rooftop rainwater harvesting which is regarded as one of the viable alternative sources of water for domestic use. This paper assesses the potential economic benefits for rooftop rainwater harvesting for the City of Windhoek. The rooftop areas from four representative formal suburbs of Okuryangava (low income) in the north, Academia (middle income) in the south-central, Pioneers Park (middle income) in the south-west and Ludwigsdorf (high income) in the east, were estimated from high resolution satellite images captured from Google Earth. These estimates were used to extrapolate for the potential amount of rainwater that can be harvested in an average rainy season (i.e. December to April) in the study area. The estimated harvestable amount for each residential area was developed using a simple model that incorporates total rooftop area and estimated rainwater. The derived figure was then expressed in terms of cost per unit prices charged by the City of Windhoek. Pioneers Park attests to have the highest $\left(134 \mathrm{~m}^{3}\right)$ potential harvestable rainwater per household, while Okuryangava is estimated to harvest the least amount of $36 \mathrm{~m}^{3}$ per raining period. Given the high density of erven, however, Okuryangava has a potential to harvest approximately $920484 \mathrm{~m}^{3}$ of water per hectare, ranking this suburb second after Academia, which stands at $1120716 \mathrm{~m}^{3}$. This is a significant amount of water effectively taken from rainwater rooftop that could also provide justifiable saving to residents if used instead of tap water. It is therefore recommended that the City of Windhoek actively promotes rooftop rainwater harvesting for the benefit of residents and also as a measure to reduce storm-water runoff due to urban development.
\end{abstract}

Keywords: City of Windhoek, Rooftop Area, Rainwater Harvesting, Water Saving Cost

\section{Introduction}

The earth is covered by approximately $71 \%$ of water but only a total of $3 \%$ is fresh water (Bhandari, 2003). Fresh water is largely stored in polar ice sheets, rivers, lakes, streams, below ground as soil- and groundwater and the atmosphere. Only $0.003 \%$ of freshwater is accessible to humans, however (Bhandari, 2003). This signifies the scarcity of freshwater resources on earth. According to UNFAO (2007) around 1.2 billion people, or almost one-fifth of the world's population, live in areas of physical water scarcity, and 500 million people are approaching this situation. Additionally, 1.6 billion people, or almost one quarter of the world's population, face economic water shortage.

Global freshwater resources are facing dramatic changes as a result of global climate change, high water demands, population growth, industrialisation and urbanisation. As climate change leads to more extreme variations, water rationalization schemes through rain harvesting has been identified as an effective intervention measure towards meeting Africa's Millennium Development Goals (MwengeKahinda et al., 2007). This paper aims to assess the potential amount of rainwater that can be harvested from rooftops in the City of Windhoek. 


\subsection{Background}

Rainwater harvesting is a viable alternative freshwater source, particularly for arid countries. It is also valuable in this age were freshwater resources are under increasing pressure from pollution and over-utilization. This practice is currently taking place in many countries across the globe, especially developing countries in Africa and Asia (HRDC, 2007; Baker et al., 2007). Rainwater harvesting is relatively cheap and pollution-free. This is mainly due to the fact that as the rain falls, rainwater is collected before it is allowed to interact with the ground, where the higher potential for pollution exists. Therefore, the likeliest source of pollution and contamination of the harvested water would be the pollution inherent in the atmosphere or the unhygienic conditions of the collecting devices (HRDC, 2007).

Windhoek, Namibia's capital, has a population of approximately 300000 residents, with a growth rate of $4.44 \%$ per annum (City of Windhoek, 2010). Like much of the country, the area receives summer rainfall, mostly during the months of December to April; the average annual rainfall is approximately $360 \mathrm{~mm}$ (NORIT, 2002). Water supply for Windhoek comes from a combination of three sources.

Since the early 1970s, the main water source is surface water collected in the dams around Windhoek (mainly Von Bach). The second source is the water acquired from recycling of waste water at Goreangab water reclamation plant, whilst the third source is borehole water (Louw, 2013). All these sources are delicate and vulnerable to environmental or economic factors. Water recycling, for example, has many economic implications due to the expensive nature of the recycling of waste water to potable quality, whilst the aquifers in Windhoek are said to be very vulnerable to pollution because they are shallow, and unprotected (Murray \& Tredoux, 2004; Mapani, 2008).

With increasing growing population, demand for water will rise proportionally. Rainwater harvesting could therefore be another source of water for the residents of Windhoek. The economic benefits could arise from the fact that residents will save on potable water supplied by the city, through the usage of rain water on gardens, laundry as well as on most activities taking place outside the household. The city will also benefit by saving on the money needed to recycle the water required to meet the demand of the
Windhoek residents. Despite its tremendous potential, rainwater harvesting has not received adequate recognition in Namibia (New Era, 2012). Though rainwater can be harvested from many surfaces, rooftop harvesting systems tend to be the most commonly used (Baker et al., 2007; Verlag, 2002). The technique has proven to work well in most countries and this can be an excellent strategy for adoption to Namibia.

\section{Methodology}

To estimate the potential amount of rainwater that can be harvested from rooftops within the four selected suburbs of Okuryangava, Academia, Ludwigsdorf and Pioneers Park, data were collected as follows: three sub-tiles of satellite images covering part of the City of Windhoek were onscreen captured from Google Earth 2009. These sub-tiles cover a 3.1 ha area of Okuryangava, 13.98 ha section of Ludwigsdorf and a 14.57 ha area of Pioneers Park and Academia combined. These suburbs were selected based on income classification per suburb, where low income suburb was represented by Okuryangava, middle income suburb constitute of Pioneers Park and Academia, while Ludwigsdorf correspond to a high income suburb.

The onscreen-captured image tiles were imported into ILWIS 3.3 (ITC, the Netherlands), an object oriented, raster-based Remote Sensing/GIS package. The images were then geo-referenced to a UTM coordinate system, yielding a re-sampled spatial resolution of less than one meter. The process of on-screen digitizing focused on roofs of the largest, contiguous building in each erven. This was necessitated under the assumption that installations for water harvesting would be more beneficial from one large surface area. Due to rainwater intercept and stem flow, only the unobstructed roof area was digitized where no tree(s) covered the roof. In essence, the average roof area for each erven would thus be marginally under-estimated under this approach. The digitized roof area for each suburb was then converted to polygons and sizes were calculated using the same GIS program. For the estimation of the potential amount of rainwater that can be harvested per house or hector in each suburb, the following formula was used:

$$
\text { Water volume }(L)=\text { Average annual rainfall }(\mathrm{mm}) x \text { coefficient of runoff } x \text { roof area }\left(\mathrm{m}^{2}\right)
$$

(Equation 1)

A coefficient of rooftop runoff of 0.9 applicable to most buildings structure and used in literature (Romsey, 2010) was used to obtain a rough estimate. (Note: $\left.1 \mathrm{~m}^{3}=1000 \mathrm{~L}\right)$.

The cost of potable domestic tap water per $\mathrm{m}^{3}$ as provided by the Municipality Table 1, was used to estimate the saving amount $(\mathrm{N} \$)$ from the municipal water tariffs per average rainy season if this rainwater is collected and used instead of tap water. For the estimation of the saving amount (N\$) to residents per average house the following formula was used:

Saving amount $(N \$)=$ Water volume collected from rooftop area $\left(m^{3}\right)^{*}$ Cost of one cube water (N\$) (Equation 2)

\section{Results}

Pertinent measurements and derivatives from the four selected suburbs attest that Okuryangava, Ludwigsdorf, Academia and Pioneers Park had the following average roof areas sizes for house as follows: $111.51 \mathrm{~m}^{2}, 258.40 \mathrm{~m}^{2}$, $394.88 \mathrm{~m}^{2}, 413.31 \mathrm{~m}^{2}$, respectively. While per hector, the 
roof area sizes were $2841 \mathrm{~m}^{2}, 1737 \mathrm{~m}^{2}, 3457 \mathrm{~m}^{2}, 2633 \mathrm{~m}^{2}$ respectively. The number of roof structure per hector estimates are $25.5,6.7,8.8$ and 6.4 , respectively.

\subsection{Potential Harvestable Rainwater}

The estimates of the average potential amount of rainwater that can be harvested from rooftop area per household $\left(\mathrm{m}^{2}\right)$ are shown in Figure 1. These calculations are based on the annual average total rainfall of Windhoek (360 mm).

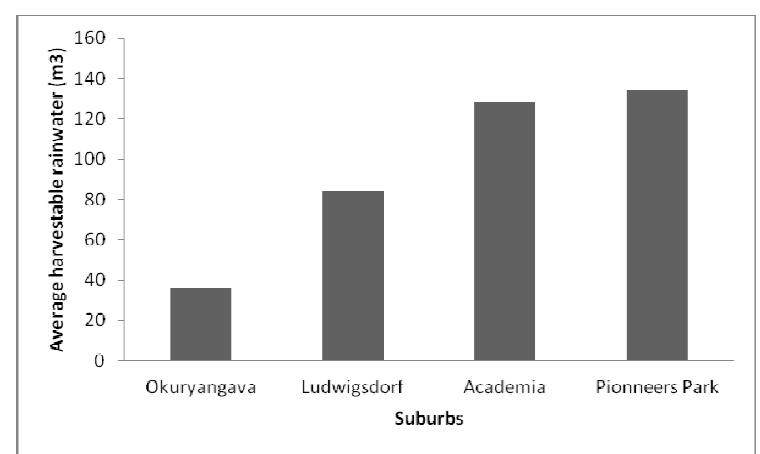

Figure 1. Average harvestable rainwater per household in each suburb per annum

The average amount of rainwater that can be harvested per household in each suburb per year is highest in Pioneers Park followed by Academia with estimated water volume of $134 \mathrm{~m}^{3}$ and $128 \mathrm{~m}^{3}$, respectively. Ludwigsdorf is estimated to yield an amount of $84 \mathrm{~m}^{3}$ while the minimal volume of harvestable rainwater for Okuryangava is $36 \mathrm{~m}^{3}$.

The comparison of suburbs with regards to the estimated average amount of rainwater that can be harvested per hectare is showed in Figure 2. Academia suburb tends to have the greatest rooftop area per hectare in contrast to all other suburbs, followed by Okuryangava, Pioneers Park and the least Ludwigsdorf with an estimated rainwater amount of $1120716 \mathrm{~m}^{3}, 920484 \mathrm{~m}^{3}, 853092 \mathrm{~m}^{3}$, and $562788 \mathrm{~m}^{3}$, respectively.

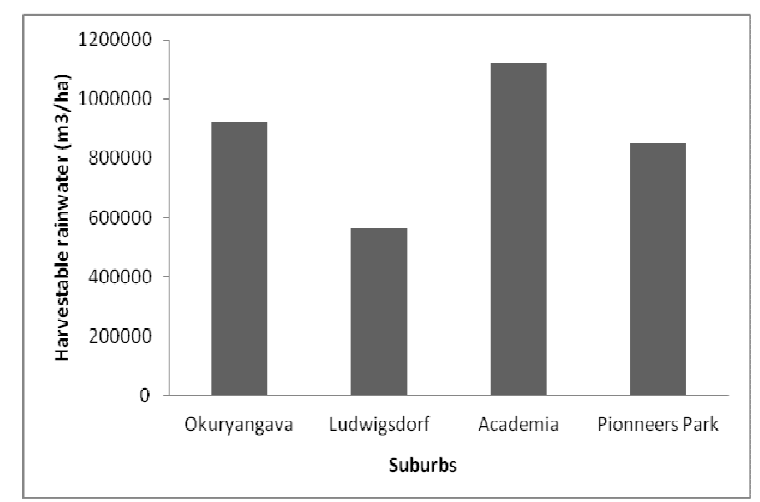

Figure 2. Potentially harvestable rainwater per hectare in each suburb

\subsection{Saving Amount from Municipal Water Tariffs (NS)}

For the City of Windhoek the potable water consumption tariffs for domestic use is shown in Table 1.

Table 1. Water consumption tariffs for the Municipality of Windhoek (Source: City of Windhoek, 2010).

\begin{tabular}{|c|c|c|c|c|}
\hline \multicolumn{5}{|c|}{ WATER CONSUMPTION TARIFFS- POTABLE } \\
\hline Tariff Code & Consumer Description & Tariff per $\mathbf{~ m}^{3}$ & VAT & Total \\
\hline \multirow{3}{*}{ WC 10} & $\begin{array}{l}\text { Domestic } \\
0-0.200 \mathrm{~m}^{3} \text { per day }\left(0-6 \mathrm{~m}^{3} \text { p.m. }\right)\end{array}$ & 8.08 & $0 \%$ & 8.08 \\
\hline & $0.201-1.50 \mathrm{~m}^{3}$ per day $\left(6-45 \mathrm{~m}^{3}\right.$ p.m. $)$ & 13.44 & $0 \%$ & 13.44 \\
\hline & More than $1.50 \mathrm{~m}^{3}$ per day $\left(>45 \mathrm{~m}^{3}\right.$ p.m.) & 24.76 & $0 \%$ & 24.76 \\
\hline
\end{tabular}

The potential amount of water that can be harvested from rooftop areas of building structure is calculated in terms of its cost as tap water to estimate the probable amount of money to be saved instead of using tap water. The calculation on cost saving was based on the quantity of water usage consumption as set up by the City of Windhoek, Municipality (Table 1).

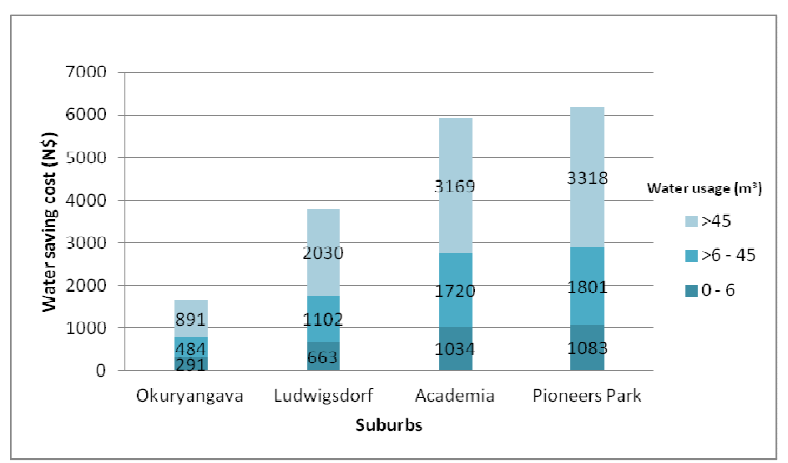

Figure 3. Average water saves per house in each suburb per rainy season
The saved amount per rainy season was determined based on the water volume collected from the rooftop area. It is evident from Figure 3, that the Municipal water consumption tariffs are based on water usages $\left(\mathrm{m}^{3}\right)$. The comparison of saved amount in each suburb based on municipal water tariffs (Table 1) shows that more saves is to be obtained at water usage of $>45 \mathrm{~m}^{3}$ in Pioneers Park and Academia, with N\$3318 and N\$3169, respectively. Whereas, residents for Ludwigsdorf and Okuryangava can save about $\mathrm{N} \$ 3169$ and N\$891, respectively, when assessed at the maximum tariff price for water usage $\left(>45 \mathrm{~m}^{3}\right)$.

\section{Discussion}

The GIS analysis employed in this study was essential for a systematic evaluation of roof rainwater harvesting in the City of Windhoek. Through the application of GIS it was possible to estimate the total amount of water harvestable at the household level as well as per hector in 
each suburb. As a result, low income areas with limited roof sizes per household, such as Okuryangava, emerged to have relatively less harvestable amount of $36 \mathrm{~m}^{3}$, whereas middle income suburbs per household was dominated by larger single story buildings, such as Pioneers Park and Academia, and have a potential to harvest as much as 130 $\mathrm{m}^{3}$ of water per rainy season. High income suburbs had mostly double story buildings covering relatively a smaller surface area, such as Ludwigsdorf can be expected to harvest an amount of approximately $80 \mathrm{~m}^{3}$ per rainy period. Okuryangava area constitute of high density of erven per hector in comparison to all other suburbs. Thus, the water collection potential surpassed Ludwigsdorf and Pioneers Park with an amount of $920484 \mathrm{~m}^{3}$. Though, Academia had the highest water collection potential which amount to $1120716 \mathrm{~m}^{3}$ per hector. This is a significant amount of potential rain water that could be channeled to good use.

Considering the calculated water save per household if rainwater is collected and used, a justifiable saving can be deduced per rainy season by individual resident. These values can be escalated if measurement is calculated per hector, though not considered in this study as these are mere estimation. This quantity of water would make considerable savings towards watering of gardens, car washing and laundry, which are listed as some of the most water consuming activities in Windhoek (Uhlendahl et al., 2010) and may not require purified water.

Currently, only a few residents located in formal areas of the city are reported to harvest rainwater from roofs (New Era, 2012). This limited usage of rainwater harvesting was in part attributed to economic factors and lack of awareness. The initial cost, which includes the acquisition of storage tank and installation, may far exceed the annual expenditure (averaging approximately $\mathrm{N} \$ 3000$ per household) for water consumption at present. Valued in short term perspective, individual household may therefore not justify investing in roof water harvesting. A general misconception in Namibia that residents in urban areas are not allowed to harvest rainwater has been recently dispelled by the City of Windhoek (New Era, 2012). The only condition attached to such practice is that harvested water shall not be connected to any of the municipal supply systems and can only be used for private consumption. Residents are thus allowed to liberally make use of water harvested from roofs at a household level.

\section{Conclusion}

The City of Windhoek has tremendous technical potential for rooftop rainwater harvesting. Based on the estimated results from this study it is envisaged that Windhoek residents can potentially collect substantial amount of rainwater and further more save on water cost, particularly towards usage that does not require purified water. Whilst it is unlikely that all of this potential will be developed shortly, it is evident that rainwater harvesting can provide justifiable amount of water to Windhoek residents.

\section{Recommendation}

In order to facilitate the implementation and swift operationalization of rainwater harvesting practices, the City of Windhoek need to provide support and assistance to its resident which can include mandatory installation of water tanks on all new houses or inclusion of rainwater harvesting designs to all future settlements. Furthermore, voluntary (with incentives) installation of water tanks on existing houses is also recommended. Significantly, water saving campaigns should be necessitated by the City of Windhoek to ensure that residents are educated on the significance of adopting strategies for rainwater harvesting as an additional source of water for their household use.

\section{References}

[1] S. Baker, E. Grygorcewicz, G. Opperman and V. Ward. "Rainwater Harvesting in the Informal Settlements of Windhoek, Namibia". Retrieved 31 March 2011, from website:

http://www.wpi.edu/Pubs/E-project/Available/E-project-051207-15 2911/unrestricted/report.pdf, 2007.

[2] B.B. Bhandari. "What is happening to our Freshwater Resources? Institute for Global Strategies. Environmental Education project". Tokyo, 2003.

[3] City of Windhoek. "City Development and Planning". Retrieved 7 April 2010, from website: http://www.windhoekcc.org.na/default.aspx?page=42, 2010.

[4] VV. Berlag. "Rainwater harvesting facilities part 1: design, construction, operation, and maintenance". Berlin, Deutsches Institut für Normunge (DIN), 2002.

[5] Habitat Research \& Development Centre (HRDC). "Rainwater Harvesting in Namibia". Newsletter of the Namibia National habitat committee Vol. 3, No. 3, 2007.

[6] D. Louw. 'The Windhoek Aquifer: An important source in the water supply to the City of Windhoek". Namibia Scientific Society. Windhoek. 2013. (Presentation).

[7] B.S. Mapani and U. Schreiber. "Management of city aquifers from anthropogenic activities: Example of the Windhoek aquifer, Namibia". Journal of Physics and Chemistry of the Earth, volume 33, 674-686, 2008.

[8] E.C. Murray and G. Tredoux. "Planning Water Resource Management: The Case for Managing Aquifer Recharge". Proceedings of the 2004 Water Institute of Southern Africa (WISA) Biennial Conference, 2 - 5 May 2004. Cape Town. 430-437, 2004.

[9] J. MwengeKahinda, A.E. Taigbenu and R.J. Boroto. "Domestic rainwater harvesting to improve water supply in rural South Africa". Physics and Chemistry of the Earth, 32: 1050-1057, 2007.

[10] New Era. "Harvesting rainwater in Windhoek a cheaper option". Retrieved 10 November 2012, from website: http://www.infrastructurene.ws/2012/07/03/harvesting-rainw ater- in-windhoek-a-cheaper-option/, 2012. 
[11] NORIT. "New Goreagab Water Reclamation Plant". Retrieved 7 April 2010, from website: http://www.norit.com/import/assetmanager/5/5565/02-

CASE_HISTORY_GoreangabB.pdfl, 2002.

[12] Romsey. "Rainfall harvesting calculator". Retrieved 12 February 2011, from website:

http://home.iprimus.com.au/foo7/tank2.html, 2010.
[13] T. Uhlendahl, D. Ziegelmayer, A. Wienecke, L. Mawisa and P. du Pisani. "Water consumption Windhoek 2010". Institute of Cultural Geography, Berlin: Albert-Ludwigs University of Freiburg, 2010.

[14] United Nations Food and Agriculture Organization (UNFAO). "Coping With Global Water Scarcity". Rome, FAO, 2007. 